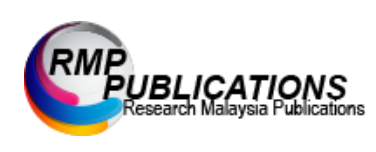

Journal of Social Science and Humanities, 4 (4): 06-10, 2021

e-ISSN: 2600 - 9056

(C) RMP Publications, 2021

DOI: $10.26666 / \mathrm{rmp} . j s s h .2021 .4 .2$

\title{
Religiosity and Income among Muslims: A Baseline-Study from Malaysia
}

\author{
Makmor Tumin, Ahmad Farid Osman and Nawi Abdullah \\ Faculty of Business and Economics, University of Malaya \\ 50603 Kuala Lumpur, Malaysia.
}

\begin{abstract}
Several theories and empirical studies have established a negative association between income and religiosity, whereby increased income has been associated with decreased religiosity. The bulk of previous empirical studies which were based on data from the Pew Research Centre have been country-level analyses with only a few Muslim-majority countries included. This baseline study provides a preliminary examination of the relationship between income and religiosity at the individual level among Muslim populations. The study utilizes data collected using a self-administrated questionnaire distributed online in June 2020. The multivariate OLS regressions demonstrate that, at the individual level and among Muslims, the association between religiosity and income is not linear, but quadratic. An increase in income is associated with a decline in religiosity up to a turning point, where the increase in income is associated with increased religiosity, forming a U-shaped relationship.
\end{abstract}

\section{Key words: Muslim, Islam, Income, Poor, Religiosity, Secularization theory}

\section{INTRODUCTION}

Recent works in the literature indicate that with an increasing income, there is a sudden decline in religion [1]. However, it excludes the phenomenon of a spiritual focus [2]. This explains that people still believe in, but do not feel like, belonging to specific identities of religion. Several theories and empirical studies have attempted to decode the linkage between income and religiosity, most of which argue that an increase in income is associated with reduced religiosity [3, 4]. However, the discussion over this topic remains controversial, and effort must be made to clearly distinguish between religious individuals and religious countries, and between wealthy individuals and wealthy countries.

The argument about the interaction between religiosity and income has been taken from various angles, including economics, development, and psychology. The secularization theory, for instance, argues that, as a result of development, more people become richer and break out of poverty, which results in a decline in their needs for religion.

In line with this, some of earlier psychologists such as Sigmund Freud argue that religiosity is a form of response to anxiety and stress from life challenges [5]. In other words, people embrace religion as a form of escape from their miseries and hardships. This notion is similar to how Karl Marx perceived religion in his very thought-provoking statement, "religion is the opium of the people."

Empirical research seems to be in support of the abovementioned argument about the negative effect of income on religiosity [3]. In a cross-country study, Herzer and Strulik [4] found that there is a causal relationship between income and religiosity, and that this relationship runs in both ways, where increasing income causes a decline in religiosity, and declining religiosity causes an increase in income.

Although the above-mentioned theories and empirics support the negative relationship between religiosity and income, several facts indicate that the relationship between religion and income might not always be negative. One of these facts stems from a survey of about 13.1 million millionaires, which found that about $2 / 3$ of them are affiliated with a religion [6]. This gives rise to an important question: if religiosity decline is associated with an increased income, why is it that the

Corresponding Author: Makmor Tumin, Department of Public Administration, Faculty of Business and Economics, University of Malaya, 50603 Kuala Lumpur, Malaysia. Tel.: +603-79673658. E-mail: makmor@um.edu.my 
world's richest people still affiliate themselves with a religion, whereas they are expected, according to the secularization theories presented above, to be religionfree?

As indicated above, most research on the relationship between income and religiosity uses data at the country level, such as that by Iannaccone [7], Lynn, Harvey, and Nyborg [8], or the Pew Research Center [9]. Our previous research, which established a completely new finding on the effect of income on religiosity, also used country-level data as well. Although country-level evidence is solid, micro evidence will provide significant support for further results at the micro-level, by dragging away the ecological fallacy and allowing for a detailed exploration of the studied phenomena. However, to complete the picture, we aim to examine the association between income and religiosity using data at the individual level.

Previous empirical research work has argued that the Muslim society has a special standing point when it comes to the relationship between income and religiosity. In other words, previous research on Muslim countries claim that religiosity among Muslims is higher than in other religions. Moreover, previous studies included only a few Muslim-majority countries in their analyses. Ipso facto, it could be argued that the abovementioned theories and findings from previous research in this area may not apply to Muslims, owing to the special nature of this religion.

Given the above arguments, the objective of this study is to examine the relationship between income and religiosity at the micro-level among Muslims. It is a baseline preliminary study that paves the way for further inquiries and, sheds light on possible directions for future research.

\section{METHODS}

To achieve the objectives, a ten-item online selfadministrated questionnaire was distributed to Muslim respondents living in Malaysia via various channels, including social media, SMS, and email. A convenient snowball sampling technique [10] was used to distribute the questionnaire between the 10th and 17th of June 2020. One of the reasons for using the online-based questionnaire is the COVID-19 pandemic, where reaching respondents face-to-face was almost an impossible task with the lockdown imposed in Malaysia during the study period.

Respondents were first asked six questions about their demographic and socioeconomic information, including their monthly income. Next, respondents were presented with four questions assessing their religiosity, in the form of a 5-point Likert scale; see the appendix at the end of this paper. The first question measures the respondents' self-rated level of religiosity. The second question measures respondents' self-rated importance of religion in their lives. The third and fourth questions measure the respondents' commitment towards performing daily prayers, and attending religious services (including religious rituals such as Friday prayers and any other remembrance rituals). The overall level of religiosity for each respondent were calculated based on the average scores for the aforementioned four questions of religiosity.

The main target was to recruit 40 respondents for the sake of the preliminary study. However, we successfully reached 46 respondents, from which only one was omitted due to response inconsistency. Therefore, we ended up with 45 valid responses to be included in the analysis.

Descriptive statistics were used to present the respondents' characteristics and the summary of the religiosity variables. To examine the relationship between religiosity and income, multiple ordinary least square regression was carried out. Religiosity index, which we constructed out of the four questions on religiosity, was the dependent variable for all regressions. Income was the main independent variable. Squared income was also included, acting as an independent variable in the regression analysis to examine the possible nonlinear U-shaped association between income and religiosity at the micro-level. Education, age, and gender were controlled in this study. Since the sample size is relatively small, and fit for a preliminary study, we use a $10 \%$ significance level as a criterion.

\section{RESULTS}

Table 1 presents the descriptive statistics of the respondents' demographic and socio-economic characteristics. About $45 \%$ of the respondents are male, while the remaining $55 \%$ are female. The majority of respondents (71.1\%) are Malaysians. Two-thirds of the respondents have a tertiary education or above. The mean age of respondents was 35.3 years, ranging from 27 to 53. Respondents' income ranges from 0 to 13,000 MYR, with a mean individual monthly income of 4,104.40 MYR.

Table 2 illustrates the descriptive statistics of the religiosity questions. The last row of Table 2 illustrates the descriptive statistics of where the indicator is, which we have constructed by averaging the respondents' scores for the four questions listed in the same table. 
Table 1: Descriptive statistics of the respondents' profiles

\begin{tabular}{lcc}
\hline \hline & No. & $\%$ \\
\hline Gender & 20 & $44.4 \%$ \\
Male & 25 & $55.6 \%$ \\
Nationality & & \\
Malaysian & 32 & $71.1 \%$ \\
Non-Malaysian & 13 & $28.9 \%$ \\
Education & & \\
Pre-tertiary & 15 & $33.3 \%$ \\
Tertiary and above & 30 & $66.7 \%$ \\
\hline & Mean & $($ Min- \\
& {$[$ SD] } & Max) \\
\cline { 2 - 3 } Age (Years) & 35.3 & $(27-53)$ \\
Individual Income & {$[7.73]$} & \\
(MYR)* & 4104.4 & $(0-13000)$ \\
\hline \hline
\end{tabular}

Notes: * Malaysian Ringgit (4.3 MYR $\approx 1 \mathrm{USD}$, as of June 2020)

Source: Authors' survey.

Table 2: Descriptive statistics of the religiosity items and religiosity index.

\begin{tabular}{lccccc}
\hline \hline & $\mathbf{N}$ & Min & Max & Mean & SD \\
\hline $\begin{array}{l}\text { How important is } \\
\text { religion to you? }\end{array}$ & 45 & 3.00 & 5.00 & 4.56 & 0.76 \\
$\begin{array}{l}\text { How often do you } \\
\text { attend religious }\end{array}$ & 45 & 1.00 & 5.00 & 3.33 & 1.31 \\
$\begin{array}{l}\text { services? } \\
\text { How often do you } \\
\text { pray? }\end{array}$ & 45 & 5.00 & 5.00 & 5.00 & 0.00 \\
$\begin{array}{l}\text { How religious do } \\
\text { you think you } \\
\text { are? }\end{array}$ & 45 & 2.00 & 4.00 & 3.40 & 0.54 \\
Religiosity index & 45 & 3.00 & 4.75 & 4.07 & 0.43 \\
\hline \hline
\end{tabular}

Source: Authors' survey.
Table 3: Association between religiosity index and income, multivariate OLS regressions, $\mathrm{N}=45$.

\begin{tabular}{lccc}
\hline \hline & \multicolumn{3}{c}{$\beta(P$-value $)$} \\
\hline \multirow{2}{*}{ Income } & {$[1]$} & {$[2]$} & {$[3]$} \\
\cline { 2 - 4 } Income^2 & 0.019 & -0.117 & -0.088 \\
& $(0.429)$ & $(\mathbf{0 . 0 6 7 )}$ & $(0.230)$ \\
Age & - & 0.013 & 0.013 \\
& & $\mathbf{( 0 . 0 2 4 )}$ & $(0.049)$ \\
Gender & - & - & -0.009 \\
& & & $(0.486)$ \\
Education & - & - & -0.105 \\
& & & $(0.502)$ \\
Constant & 3.995 & 4.237 & -0.145 \\
& $(0.000)$ & $(0.000)$ & $(0.000)$ \\
Model $P$-value & & & $0.374)$ \\
(F-statistic) & 0.429 & 0.056 & 0.225 \\
\hline \hline
\end{tabular}

Notes: The dependent variable is the religiosity index. The use of the squared term does not violate the assumption of OLS regressions; see Gujarati [10].

Source: Authors' survey.

Table 3 presents the results of multivariate OLS regressions, where the dependent variable is the religiosity index. The first column in Table 3 presents a regression where income is the only independent variable; it shows that income is not a significant predictor of religiosity $(\mathrm{P}=0.429)$. In the second column, the squared term of income is added into the regression. Both income and Squared income are significant predictors of religiosity $(\mathrm{P}<0.1)$.

It is thus obvious that the relationship between income and religiosity is not linear, but quadratic. Column 3 presents a regression similar to the one in Column 2, but with controls, namely, gender, education, and age. The results show that none of the aforementioned controls is significantly associated with religiosity. 


\section{DISCUSSION AND CONCLUSIONS}

Although the sample of this preliminary study is small, it still provides interesting results. It is important to note that the results provided from this baseline preliminary study should be read carefully, since it does not provide the final conclusion for this context. Such conclusions can only be drawn from a full sample size. However, the findings of this study provide an interesting and insightful outcome that paves the way for future studies and improvements in understanding the relationship between income and religiosity.

Another consideration that should be exercised is that this study was conducted in Malaysia, a Muslimmajority country where about $60 \%$ of the population are Muslims. In addition to that, Malaysia is the most developed and modern Muslim-majority country in the world, with an average per capita GDP of 27,536 (constant 2017 international USD, PPP) [11]. Therefore, the results of this study may not apply to other Muslim-majority countries. In other words, caution should be exercised before generalizing the results of this study to the Muslim population in other parts of the world.

It is worthy to note that the respondents' responses to the question on the performance of their daily prayers do not show any form of variation. All the respondents stated that they do perform their prayers daily, regardless of their level of self-reported religiosity and the importance of religion to them. Performing the daily prayers is one of the important pillars of Islam. Muslims are required to pray five times a day and attend compulsorily (for males) religious service every Friday (also known as Jumma prayer). Muslims are also encouraged to perform their five daily prayers as a group in mosques or prayer rooms. Performing daily prayers in a group is considered a higher-order religiosity than performing them individually. Males and females are encouraged to attend other religious services such as remembrance rituals (Yaasin recitation, tahlil prayer, etc.).

The questions used in this preliminary study to measure the respondents' religious commitments were derived from previous research and surveys, mainly from the Pew Research Center [9], where the bulk of surveyed nations are not majority-Muslim countries. Thus, the questions were fitted to better serve in these settings. The results of this preliminary study suggests that, among Muslims, particularly in Malaysia, questions about the number of performed prayers per day and the number of times they performed their daily prayers in a group are more relevant and could bring better improvement to the measurements of religiosity, rather than simply questioning if a person performed their daily prayers or not, which seems to better fit other religions than Islam. Since surveys done by other research centres such as the World Values Survey, the European Values Study, the European Social Survey, the International Social Survey Programme, etc. provide data at the individual level, findings in this research should be compared with those available data as well. An important note which should be made is that the sample does not include very high-income respondents, where the highest income reported among the respondents is 13,000 MYR. Given that the average income of the Malaysian household is 7,901 MYR [12], and the Gini index is about 41 [11], we expect that a full sample size would include people with an income much higher than 13,000 MYR, as obtained in this preliminary study.

\section{ACKNOWLEDGMENTS}

We would like to acknowledge the financial support provided by Ungku Aziz Centre for Development Studies, University of Malaya [Research Grant: PD0052018] for the research, authorship, and/or publication of this article. We also thank Mr. Khaled Tafran for preparing the draft of the paper.

\section{REFERENCES}

[1] Wilkins-Laflamme, S., 2021. Digital religion among US and Canadian millennial adults. Review of Religious Research.

[2] Inglehart, R. F., 2020. Religion's sudden decline: What's causing it, and what comes next?. Oxford: Oxford University Press.

[3] Barber, N. 2011. A cross-national test of the uncertainty hypothesis of religious belief. CrossCultural Research, 45(3): 318-333.

[4] Herzer, D. and H. Strulik. 2017. Religiosity and income: a panel cointegration and causality analysis. Applied Economics, 49(30): 2922-2938.

[5] Frued, S., 1927. The future of an illusion (J. Strachey, Ed.). New York: Norton Company Inc.

[6] Frank, R. 2015. The religion of millionaires. https://www.cnbc.com/2015/01/14/the-religion-ofmillionaires-.html. Accessed April 2020.

[7] Iannaccone, L. R. 2003. Looking backward: A crossnational study of religious trends. Unpublished Working Paper, George Mason University, July.

[8] Lynn, R., J. Harvey, and H. Nyborg. 2009. Average intelligence predicts atheism rates across 137 nations. Intelligence, 37(1): 11-15. 
[9] Hackett, C., et. al. 2018. The age gap in religion around the world. Washington, DC: Pew Research Center.

[10] Dattalo, P. 2008. Determining sample size: Balancing power, precision, and practicality. New York: Oxford University Press.

[11] World Bank. GDP per capita. https://data.worldbank.org/indicator/NY.GDP.PCA P.CD. Accessed August 2019.
[12] Department of Statistics Malaysia. 2020. Household Income \& Basic Amenities Survey Report 2019.

https://www.dosm.gov.my/v1/index.php?r=column/ cthemeByCat \&cat=120\&bul_id=TU00TmRhQ1N5 TUxHVWN0T2VjbXJYZz09\&menu_id=amVoW U54UT10a21NWmdhMjFMMWcyZz09. Accessed September 2020.

[13] Gujarati, D. N., 2004. Basic Econometrics (4th ed.). New York: The McGraw-Hill Companies. 